\title{
Optimization of Nonanimal Test Methods for Next-Generation Tobacco Products Requires Scientific Cooperation Among All Stakeholders
}

\author{
Rodger D. Curren and Erin H. Hill
}

Dear Editor:

$\mathbf{T}$ HE U.S. Food AND Drug Administration's (FDA) new regulations for e-cigarettes, cigars, and all other tobacco products offer an opportunity to employ the use of predictive in vitro tools to help determine the effects of these products on human health. Although a limited number of in vitro methods are currently used by regulatory agencies in the assessment of conventional tobacco products, ${ }^{1}$ these new regulations — and the product types being assessed-provide the impetus to utilize these tools to a fuller extent. Many sophisticated models and approaches have been used within tobacco companies for product stewardship purposes, ${ }^{2,3}$ but their utility in regulatory decision-making has yet to be fully demonstrated. In addition, approaches with in vitro methods, as with any new regulatory method, must be standardized and validated to ensure their robustness and uniform use. Although many articles in this Special Edition focus on the use of these new methods and models, the real challenge is the acceptance of these methods by the regulatory agency.

A way forward to achieve harmonization of the performance and regulatory applicability of new in vitro methods is collaboration between industry and the regulatory agency. To this end, the Institute for In Vitro Sciences, a nonprofit

Table 1. IIVS Collaborative Workshops

Name Date Publication

Informational Workshop I: In Vitro COPD Models for Tobacco Regulatory Science ${ }^{\mathrm{a}}$

Society of Toxicology_Ancillary Meeting: Workshop Report: In Vitro COPD Models for Tobacco Regulatory Science-Highlights and Paths Forward

Technical Workshop I: In Vitro Models for Goblet Cell Hyperplasia, Mucus Production, and Ciliary Beating Assays

Society of Toxicology_Ancillary Meeting: In Vitro Models for Tobacco Regulatory Science: Collaborative Efforts in Respiratory Toxicology

Informational Workshop II: In Vitro Exposure Systems and Dosimetry Assessment Tools for Inhaled Tobacco Products
December 2014

Workshop report available for download at www.iivs.org

Behrsing, et al. Assessment of in vitro COPD models for tobacco regulatory science: workshop proceedings, conclusions, and paths forward for in vitro model use. Altern Lab Anim 2016:44;129-166

March $2015 \quad$ Discussion session only

June 2015

Pending completion of proof of concept testing

March 2016 Discussion session only

April 2016

Workshop report available for download at www.iivs.org

${ }^{a}$ Funding for this conference was made possible, in part, by the FDA through Grant 1 R13 FD 005299-01. The views expressed in written conference materials or publications, and by the speakers and moderators, do not necessarily reflect the official policies of the Department of Health and Human Services, nor does any mention of trade names, commercial practices, or organizations imply endorsement by the United States Government.

Institute for In Vitro Sciences, Inc., Gaithersburg, Maryland.

(c) Rodger D. Curren and Erin H. Hill, 2017; Published by Mary Ann Liebert, Inc. This Open Access article is distributed under the terms of the Creative Commons Attribution Noncommercial License (http://creativecommons.org/licenses/by-nc/4.0/) which permits any noncommercial use, distribution, and reproduction in any medium, provided the original author(s) and the source are credited. 
organization with a history of working in cooperation with both groups, has initiated a series of workshops to draw on the experience of industry and research institutions and to foster communication with the regulatory agency on the potential suitability of in vitro methods for regulatory decision-making. Through oral and poster presentations, the Informational Workshops allow the experiences of scientists from many fields to communicate with a broad audience, including government representatives. Follow-on Technical Workshops explore best practices among expert users and provide the information needed to design multilaboratory testing programs to standardize methodology. Dissemination of this information to the broader scientific community is a priority; therefore, proceedings from all workshops are published as both workshop summaries and in peer-reviewed journals (Table 1).

However, financial support for this collaborative program is difficult to obtain. As many academic and research institution representatives have restrictions on attending meetings sponsored by tobacco companies, direct funding from industry is not feasible. Although the FDA has a Small Conference Grants Program - which funded, in part, our first informational workshop - the meeting must be fully planned before the grant will be given. Therefore, an institution must risk holding the meeting on its own if the grant is not awarded. The science explored in the Technical Workshops is highly relevant and applicable; however, it does not reach the high bar of "innovativeness" to qualify for NIH grants. As the outcomes from these collaborative efforts are highly beneficial to both industry and regulators, new funding processes should be developed.
The successes of the first workshops support our view that cooperation from the regulatory agency, industry, and research institutions will lead to the optimization of nonanimal test methods and their eventual use for regulatory decision-making.

\section{Author Disclosure Statement}

The authors are employed by a non-profit institute which receives contributions from government and industry, as well as industry funding of fee-for-service research.

\section{References}

1. Manuppello JR, Sullivan KM. Toxicity assessment of tobacco products in vitro. Altern Lab Anim 2015:43;39-67.

2. Azzopardi D, Patel K, Jaunky T, et al. Electronic cigarette aerosol induces significantly less cytotoxicity than tobacco smoke. Toxicol Mech Methods 2016:26;477-491.

3. Zanetti F, Sewer A, Mathis C, et al. Systems toxicology assessment of the biological impact of a candidate modified risk tobacco product on human organotypic oral epithelial cultures. Chem Res Toxicol 2016:29;1252-1269.

Address correspondence to: Erin H. Hill, President Institute for In Vitro Sciences, Inc. 30 W. Watkins Mill Road, Suite 100

Gaithersburg, MD 20878

E-mail: ehill@iivs.org 